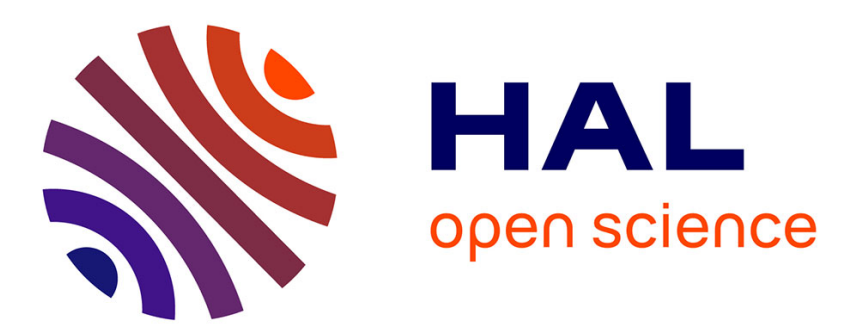

\title{
Barium titanate via thermal decomposition of Ba,Ti-precursor complexes: The nature of the intermediate phases
}

Vladislav Ischenko, Eckhard Pippel, Roberto Köferstein, Hans-Peter Abicht, Jörg Woltersdorf

\section{To cite this version:}

Vladislav Ischenko, Eckhard Pippel, Roberto Köferstein, Hans-Peter Abicht, Jörg Woltersdorf. Barium titanate via thermal decomposition of Ba,Ti-precursor complexes: The nature of the intermediate phases. Solid State Sciences, 2007, 9 (1), pp.21-26. 10.1016/j.solidstatesciences.2006.09.004 . hal02018641

\section{HAL Id: hal-02018641 \\ https://hal.science/hal-02018641}

Submitted on 14 Feb 2019

HAL is a multi-disciplinary open access archive for the deposit and dissemination of scientific research documents, whether they are published or not. The documents may come from teaching and research institutions in France or abroad, or from public or private research centers.
L'archive ouverte pluridisciplinaire HAL, est destinée au dépôt et à la diffusion de documents scientifiques de niveau recherche, publiés ou non, émanant des établissements d'enseignement et de recherche français ou étrangers, des laboratoires publics ou privés. 


\title{
Barium titanate via thermal decomposition of Ba,Ti- precursor complexes: The nature of the intermediate phases
}

Vladislav Ischenko, Eckhard Pippel, Roberto Köferstein, Hans-Peter Abicht, Jörg Woltersdorf

Solid State Sciences 9 (2007) 21-26

doi:10.1016/j.solidstatesciences.2006.09.004

\begin{abstract}
The thermal decomposition of Ba,Ti-precursor complexes, containing organic ligands and suitable for the single-source preparation of nanocrystalline $\mathrm{BaTiO}_{3}$, leads firstly to the segregation of specific Ba-rich and Ti-rich phases. Quantitative electron energy loss spectroscopy and powder X-ray diffraction data indicated that the (i) Ba-rich phase is a $\mathrm{BaO}$ stabilised variant of the calcite-type high-temperature modification of $\mathrm{BaCO}_{3}$ and (ii) Ti-rich phases are represented by low crystalline barium titanates with the general Ba:Ti ratio close to 1:4. The subsequent solid state reaction between these phases results then in the formation of $\mathrm{BaTiO}_{3}$.
\end{abstract}

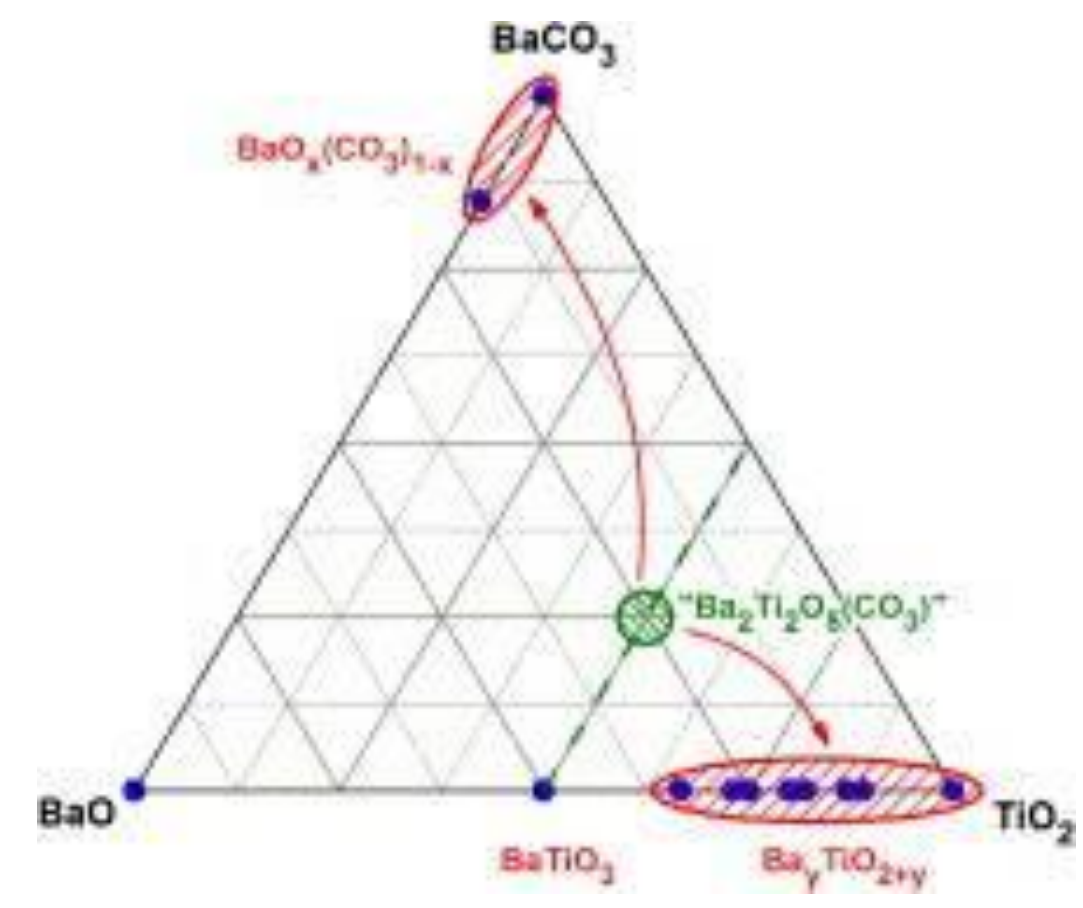




\title{
Barium titanate via thermal decomposition of Ba,Ti-precursor complexes: The nature of the intermediate phases
}

\author{
Vladislav Ischenko ${ }^{\mathrm{a}}$, Eckhard Pippel ${ }^{\mathrm{a}}$, Roberto Köferstein ${ }^{\mathrm{b}}$, \\ Hans-Peter Abicht ${ }^{b}, *$, Jörg Woltersdorf ${ }^{a}{ }_{*}$ \\ ${ }^{\text {a }}$ Max-Planck-Insitut fü r Mikrostrukturphysik, Weinberg 2, D-06120 Halle, Germany \\ b Fachbereich Chemie, Martin-Luther-Universität, Kurt-Mothes Str. 2, D-06120 Halle, Germany \\ Dedicated to Professor Dr. h.c. H.G. v. Schnering on the occasion of his 75 th birthday.
}

\begin{abstract}
The thermal decomposition of Ba,Ti-precursor complexes, containing organic ligands and suitable for the single-source preparation of nanocrystalline $\mathrm{BaTiO}_{3}$, leads firstly to the segregation of specific Ba-rich and Ti-rich phases. Quantitative electron energy loss spectroscopy and powder X-ray diffraction data indicated that the (i) Ba-rich phase is a BaO-stabilised variant of the calcite-type high-temperature modification of $\mathrm{BaCO}_{3}$ and (ii) Ti-rich phases are represented by low crystalline barium titanates with the general Ba:Ti ratio close to 1:4. The subsequent solid state reaction between these phases results then in the formation of $\mathrm{BaTiO}_{3}$.
\end{abstract}

Keywords: Barium titanate; Oxycarbonate; Precursor complexes; Thermal decomposition; Phase evolution; Electron energy loss spectroscopy; X-ray diffraction

\section{Introduction}

Barium titanate based ceramics are of great interest in material science for different reasons: undoped $\mathrm{BaTiO}_{3}$ has attained wide application as capacitor material, doped $\mathrm{BaTiO}_{3}$ ceramics are used for PTCR (positive temperature coefficient of resistance) devices, and solid solutions of $\mathrm{BaTiO}_{3}$ with other perovskite type compounds enable the tailoring of their properties in a wide range (e.g. the permittivity and the Curie temperature), and can modify the kinetics of phase transitions, e.g., when combining the ferroelectric $\mathrm{BaTiO}_{3}$ with the nonpolar $\mathrm{BaSnO}_{3}$ which results in a diffuse phase transition [1].

\footnotetext{
* Corresponding authors.

E-mail addresses: ischenko@mpi-halle.de (V. Ischenko), epip@mpi-halle.
}

de (E. Pippel), roberto.koeferstein@chemie.uni-halle.de (R. Köferstein), hans-peter.abicht@chemie.uni-halle.de (H.-P. Abicht),wolt@mpi-halle.de (J. Woltersdorf).
As the classical mixed oxide method for the preparation of $\mathrm{BaTiO}_{3}$ [2] generally involves inhomogeneities of the stoichiometry due to incomplete mixing and leaching of $\mathrm{Ba}^{2+}$ ions from surface-near layers [3], various alternative synthesis procedures have developed during the last decades: besides hydrothermal methods [4], sol-gel procedures [5-10], and coprecipitation techniques [11], there are also methods of thermal decomposition of organometallic precursors [12-15] which seem to have the best potential of adjusting the exact [Ba:Ti] stoichiometry. Whereas in $[12,13]$ barium titanyloxalate (BTO) was used as precursor; the method described in $[14,15]$ starts from a barium titanium double alkoxide precursor and performs the hydrolysis process using a special developed mini spray dryer. This latter method enables not only to adjust an exact [Ba:Ti] ratio of 1 , but also to produce fine-grained $\mathrm{BaTiO}_{3}$ powders with a relatively narrow grain size distribution ( $85 \%$ between 1 and $1.5 \mathrm{~mm}$ ).

However, independent of such special features, all the described procedures give indications of the transient existence 
of an intermediate reaction product occurring during the thermolysis of all the precursors in the temperature range between 500 and $600^{\circ} \mathrm{C}$, which is assumed to act as a crucial step in the phase evolution of $\mathrm{BaTiO}_{3}$ particles from precursor complexes. The observed different intermediate substances exhibit nearly the same features in their diffuse X-ray diffractograms and indicate an approximate composition of $\mathrm{Ba}_{2} \mathrm{Ti}_{2} \mathrm{O}_{5}\left(\mathrm{CO}_{3}\right)$. Therefore, this interphase species is sometimes called a barium titanium oxycarbonate phase, the characteristic of which is the object of different hypotheses.

For the first time, 30 years ago, such an oxycarbonate-like intermediate was suggested in [12] concerning the thermolysis of barium titanyl oxalate. On the other hand, 10 years ago, in [13] the existence of such a phase as a pure species is disputed, and a mixture of amorphous $\mathrm{TiO}_{2}, \mathrm{BaO}$ and $\mathrm{BaCO}_{3}$ is rather postulated. In [8] a hexagonal $\mathrm{BaTiO}_{3}$ phase, stabilised with $\mathrm{Ti}^{3+}$ ions, is assumed, whereas in [6] a fine mixture of $\mathrm{BaCO}_{3}$ and $\mathrm{TiO}_{2}$ is suggested. However, in [7] the $\mathrm{X}$-ray features are attributed again to a barium titanium oxycarbonate

phase. The observed metastable intermediate was assumed to have a structure of $\mathrm{BaTiO}_{3}$, with $\mathrm{CO}_{3}{ }^{2-}$ located inside the layer structure [9].

In a former paper on the thermal evolution concerning the alkoxide precursor spray hydrolysis method we also discussed the existence of an intermediate oxycarbonate phase [15]. As shown below, the intermediate products of the thermal decomposition of the Ba,Ti-precursor complexes are composed of very finely dispersed, poorly crystalline particles surrounded by an amorphous matrix phase, so that it is quite difficult to discern among different phases, if they form, and to detect the component segregation in the sample.

In this contribution, however, we have made an effort to determine the actual phase composition of such intermediate products in the above mentioned temperature range and to pro-vide a new insight into the transformation kinetics of such $\mathrm{Ba}$,Ti-precursor complexes, based on the results of quantitative electron energy loss spectroscopy, combined with structural considerations and a re-interpretation of the related X-ray diffraction patterns.

\section{Experimental details}

\subsection{Precursors used and conditions of thermal} decomposition

The preparation procedure for the complex precursor e barium titanium 1,2-ethanediolato complex $\left(\left[\mathrm{Ba}\left(\mathrm{C}_{2} \mathrm{H}_{6} \mathrm{O}_{2}\right)_{4}\right]\left[\mathrm{Ti}\left(\mathrm{C}_{2} \mathrm{H}_{4} \mathrm{O}_{2}\right)_{3}\right]\right)$ e has been described elsewhere [16]. This complex precursor was decomposed with a heating rate of $10 \mathrm{~K} / \mathrm{min}$ up to $410^{\circ} \mathrm{C}$ and a dwelling time of $65 \mathrm{~h}$. The resulting products of such an incomplete thermal decomposition are denoted as "intermediate products" or "intermediates" further in the discussion.

Barium titanyl oxalate $\left(\mathrm{BaTiO}\left(\mathrm{C}_{2} \mathrm{O}_{2}\right)_{2} * 4.5 \mathrm{H}_{2} \mathrm{O} / \mathrm{BTO}\right)$ was prepared by the method described in the literature [17]. The intermediate product in this case was obtained by heating
BTO at a heating rate of $10 \mathrm{~K} / \mathrm{min}$ up to $600 \mathrm{C}$ and a dwelling time of $1 \mathrm{~h}$.

\subsection{Imaging and spectroscopic characterization methods}

The peculiarities concerning microstructure and nanochemistry of the barium/titanium intermediate products were investigated by high resolution electron microscopy (HREM), electron energy loss spectroscopy (EELS), especially on nearedge fine structures (ELNES), and energy-filtered transmission electron microscopy (EFTEM). EELS was performed with an energy resolution of $0.8 \mathrm{e} 1 \mathrm{eV}$ using the Gatan imaging filter (GIF 200) attached to the transmission (TEM)/scanning transmission electron microscope (STEM) Philips CM 20 FEG operated at $200 \mathrm{keV}$. Point analyses were made in the nanoprobe mode with the electron probe of a few nanometers in diameter. For spectrum processing the software packages Digital Micrograph and EL/P of Gatan were used. The energy filter also enables the element imaging as well as the chemical-bond specific mapping (EFTEM). Filtered images were digitally recorded by a slow-scan CCD camera within the GIF 200.

Powder X-ray diffraction (XRD) pattern was recorded at $25{ }^{\circ} \mathrm{C}$ and performed by an STADI MP diffractometer from STOE with a curved crystal germanium monochromator using Co-K $\alpha 1$ radiation $(1.78896 \mathrm{~nm})$ and a degree step of 0.03 for $2 \theta$.

\section{Results and discussion}

\subsection{Morphology and phase composition of the intermediates}

Two different Ba,Ti-precursor complexes have been used to determine the phases formed at the intermediate stages of thermal decomposition and to check if a homogeneous intermediate, like the previously postulated $\mathrm{Ba}_{2} \mathrm{Ti}_{2} \mathrm{O}_{5}\left(\mathrm{CO}_{3}\right)$, is formed or if a component segregation occurs. As shown below, both

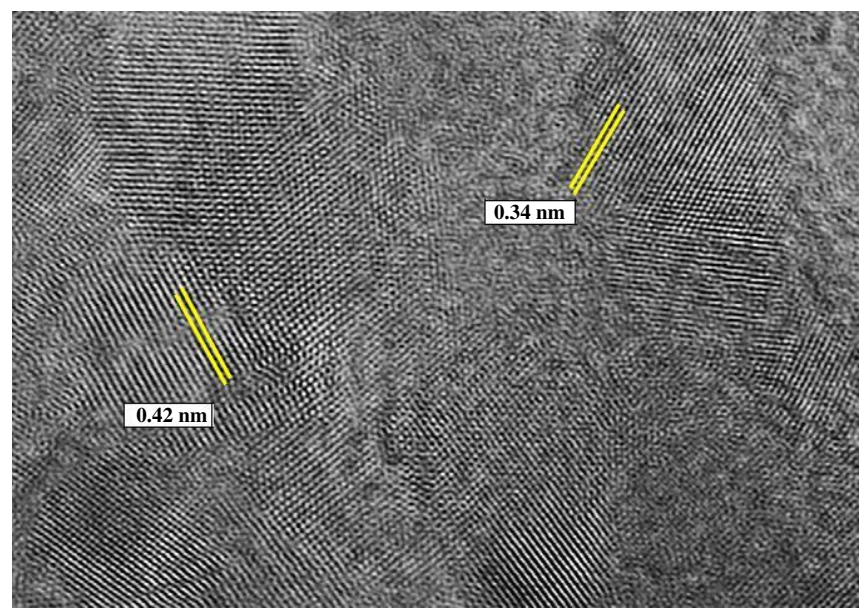

Fig. 1. HREM image of an oxalate-derived intermediate. 


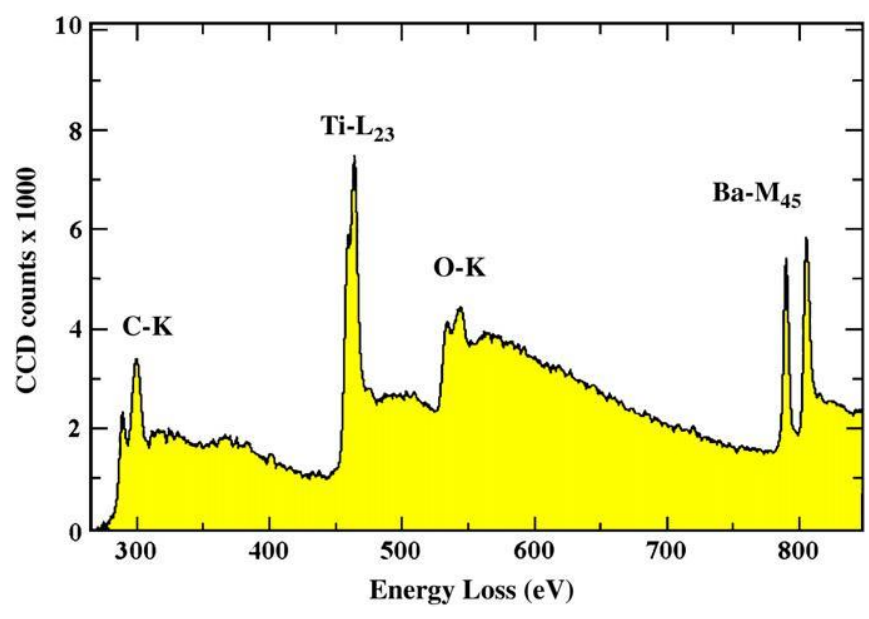

Fig. 2. EEL spectrum of an area as shown in Fig. 1.

the oxalato and the 1,2-ethanediolato precursor routes resulted in the same features, only slightly modified with respect to the morphology. This implies that a similar phase evolution may be supposed in both cases.

\subsubsection{Oxalato-derived samples}

The intermediate product formed in the course of the thermal decomposition of BTO precursor is composed of very fine nano-crystals in the order of $10 \mathrm{~nm}$ with lattice plane distances of 0.42 and $0.34 \mathrm{~nm}$, embedded in an amorphous matrix, as demonstrated in the HREM image of Fig. 1. The very small size of the crystalline and amorphous regions makes it rather difficult to perform a local phase analysis, even by using high resolution analytical methods: within the probing volume both phases can overlap and therefore cannot be separated. An example of a typical EEL spectrum is shown in Fig. 2, indicating an overall chemical composition of Ba:Ti:O:C $=1: 1: 4:<1$, which corresponds to the composition of the formerly postulated intermediate oxycarbonate phase, $\mathrm{Ba}_{2} \mathrm{Ti}_{2} \mathrm{O}_{5}\left(\mathrm{CO}_{3}\right)$, suggested in [12] and also discussed by us in [15]. The sample is, however, not homogeneous, as a segregation of $\mathrm{Ba}$ and Ti can be observed: Fig. 3 demonstrates the local variation of the Ti:Ba ratio measured by EELS along the line drawn in the STEM bright field image (upper right), clearly indicating the coexistence of Ti-rich and
Ba-rich nanoregions. The combined HREM/EFTEM image in Fig. 4 shows a two-dimensional representation of the inhomogeneous titanium distribution: the Ti-EFTEM image (red), obtained with the $\mathrm{Ti}-\mathrm{L}_{23}$ edge, is superposed to the correspond-ing HREM image, demonstrating that the Ti-rich areas are predominantly amorphous, while the Ti-depleted regions are mostly crystalline.

\subsubsection{1,2-Ethanediolato-derived samples}

The degree of $\mathrm{Ba}$ and $\mathrm{Ti}$ segregation during thermal decom-position is apparently influenced by different ligands initially present in the precursor complexes. Thus, larger agglomerates of Ba-rich and Ti-rich phases (up to some hundred nanometers) are formed from the 1,2-ethanediolato precursor, allowing more precise local chemical analysis of the phase composition.

As shown in Fig. 5, barium-rich regions have been found, containing no titanium. The related quantification yielded an element ratio close to $\mathrm{Ba}: \mathrm{C}: \mathrm{O}=1: 1: 3$; and the corresponding EELS profile is similar to that observed for the aragonite-type $\mathrm{BaCO}_{3}$ (cf. the reference curve in Fig. 5), though some differences in the O-K ELNES features can be noted, giving a hint of a possible polymorphism. An example of the second phase present in the sample, viz. the titanium rich one, is given in Fig. 6, showing an average element ratio close to Ba: Ti:O z 1:4:9, as determined by EELS along the line marked in Fig. 6 right. As demonstrated, the ratio Ba:Ti varies in a range between 1:2.5 and 1:5.5, implying that no definite crystalline phase with a fixed chemical composition is formed in the Tirich regions. In Fig. 7, the measured EELS spectrum has been compared to the pure crystalline $\mathrm{BaTi}_{4} \mathrm{O}_{9}$ reference, revealing some common features which indicate the existence of similar building blocks in the Ti-rich phases of the intermediate and in $\mathrm{BaTi}_{4} \mathrm{O}_{9}$, though the varying composition and the absence of long-range ordering in the Ti-rich phase of the intermediate do not allow the direct comparison with $\mathrm{BaTi}_{4} \mathrm{O}_{9}$.

\subsection{Powder X-ray diffraction features}

The results presented above have evidenced the $\mathrm{Ba}$ and $\mathrm{Ti}$ segregation in the intermediates of the thermal decomposition

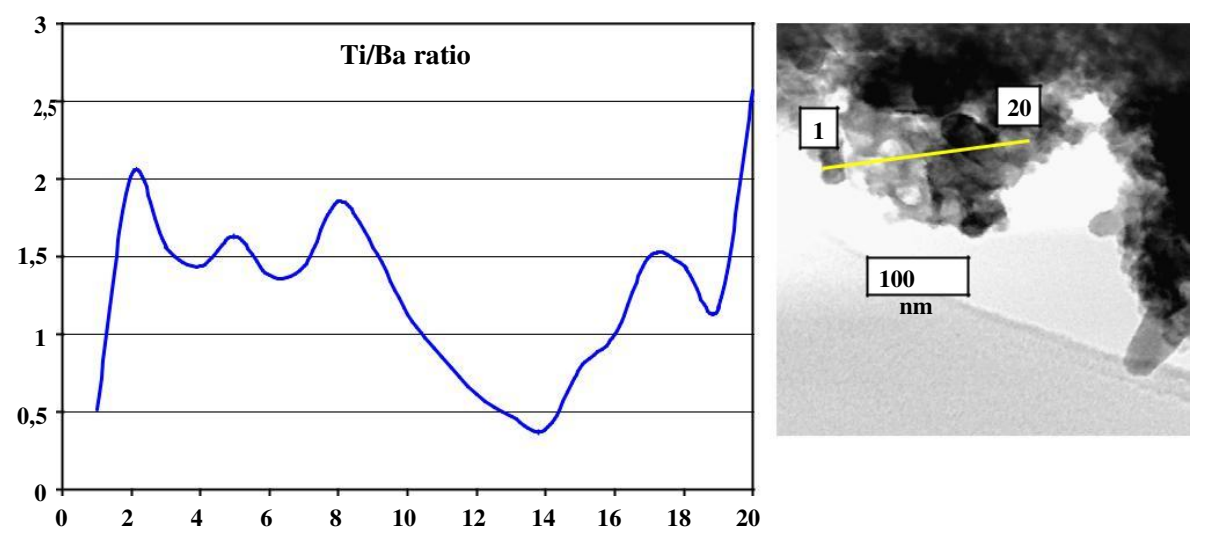

Fig. 3. Ti:Ba ratio in an oxalato-derived intermediate (upper right: STEM bright field image with the EELS scan line marked). 


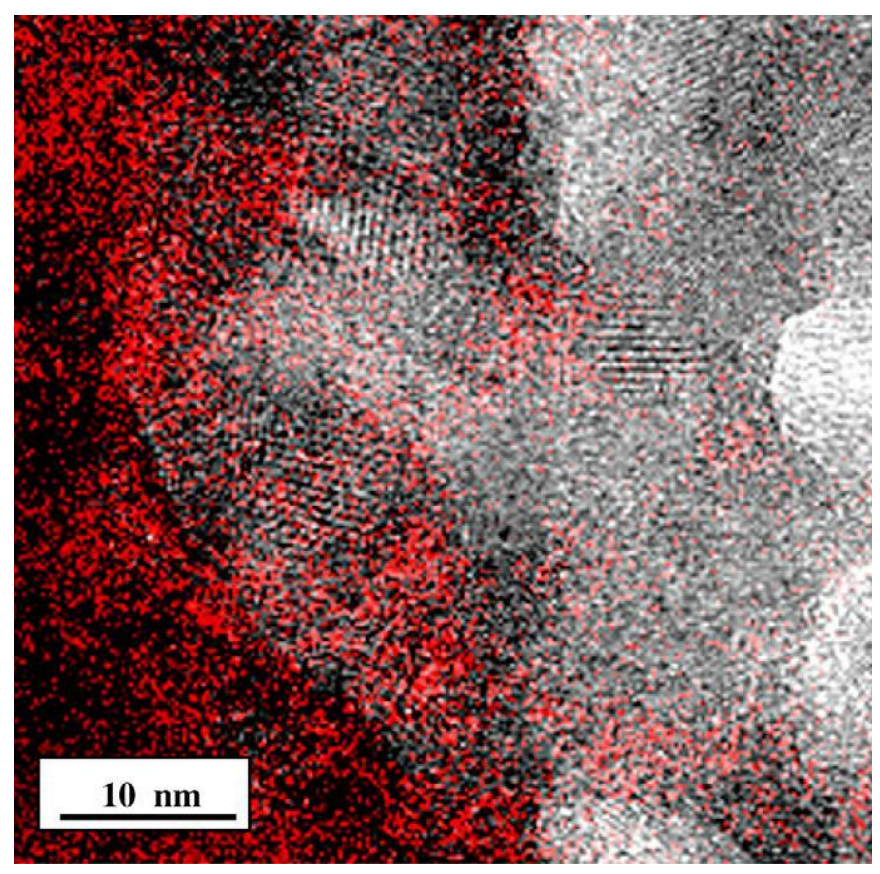

Fig. 4. Ti distribution (red) in an oxalato-derived intermediate recorded by EFTEM technique.

of Ba,Ti-precursor complexes, especially the crystalline regions have been observed to contain only little or no titanium. A corresponding crystalline phase was evidenced by powder XRD (Fig. 8, marked with stars). The distances between the atomic planes observed by HREM in Fig. $1(0.42$ and $0.34 \mathrm{~nm}$ ) correspond well to those determined from the first two diffraction maxima $\left(2 \theta=25.0\right.$ and $\left.30.7^{\circ}\right)$ in the powder XRD patterns, related to distances of 0.414 and 0.338 nm.

In spite of the more pronounced degree of component segregation in the 1,2-ethanediolato-derived intermediates, they are less crystalline, compared to BTO-derived samples. However, the presence of the crystalline phase mentioned above can be detected also in the 1,2-ethanediolato-derived intermediates, along with the traces of aragonite-type $\mathrm{BaCO}_{3}$ (whiterite) and $\mathrm{BaTiO}_{3}$ (see Fig. 8) [18]. The same powder XRD patterns, as we observed for the Ba-rich phase, have been previously reported by many authors $[7,9,15,19]$ and attributed in many cases to the postulated " $\mathrm{Ba}_{2} \mathrm{Ti}_{2} \mathrm{O}_{5}\left(\mathrm{CO}_{3}\right)$ '" phase with unknown crystal structure. In the light of the detected $\mathrm{Ba}$ and $\mathrm{Ti}$ segregation in the intermediates, we have tried to reinterpret the un-known crystalline phase and have searched for the isotypical crystal structures, corresponding to the observed XRD pattern.

The unknown crystalline phase has been found to be very similar to the high-temperature modification of $\mathrm{BaCO}_{3}$ with the calcite-type crystal structure (Fig. 8).

3.3. Structural relations between $\mathrm{BaCO}_{3}$ and the experimentally observed Ba-rich phase

Three modifications of barium carbonate are presently known from the literature [20,21]:

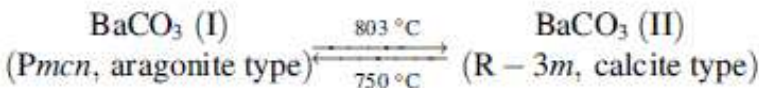

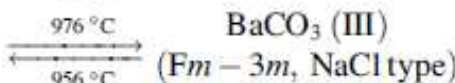

The aragonite-type modification is the only one stable under normal conditions. Two other modifications of $\mathrm{BaCO}_{3}$, of the calcite-type and of the $\mathrm{NaCl}$-type, are reversibly formed above 800 and $970^{\circ} \mathrm{C}$, respectively [20]. There is no possibility to obtain high-temperature modifications of pure $\mathrm{BaCO}_{3}$ in the metastable state at room temperature [20]. The phase transition temperature shows a slight hysteresis loop, and at least at $750^{\circ} \mathrm{C}$ a room temperature aragonite-type modification of $\mathrm{BaCO}_{3}$ is formed. However, there are some indications in the literature that different intentional or unintentional impurities in $\mathrm{BaCO}_{3}$ can stabilize the high-temperature modification of barium carbonate down to significantly lower temperatures, in some cases also down to the room temperature. For in-stance, due to the doping of barium carbonate with $\mathrm{BaSO}_{4}$ (up to $10 \mathrm{~mol} \%$ ), the $\mathrm{BaCO}_{3}$ can be obtained in its metastable state at room temperature [22]. Accordingly, the heating of a mixture of $\mathrm{BaCO}_{3}, \mathrm{SrCO}_{3}$ and $\mathrm{CaCO}_{3}$ above $750{ }^{\circ} \mathrm{C}$ resulted

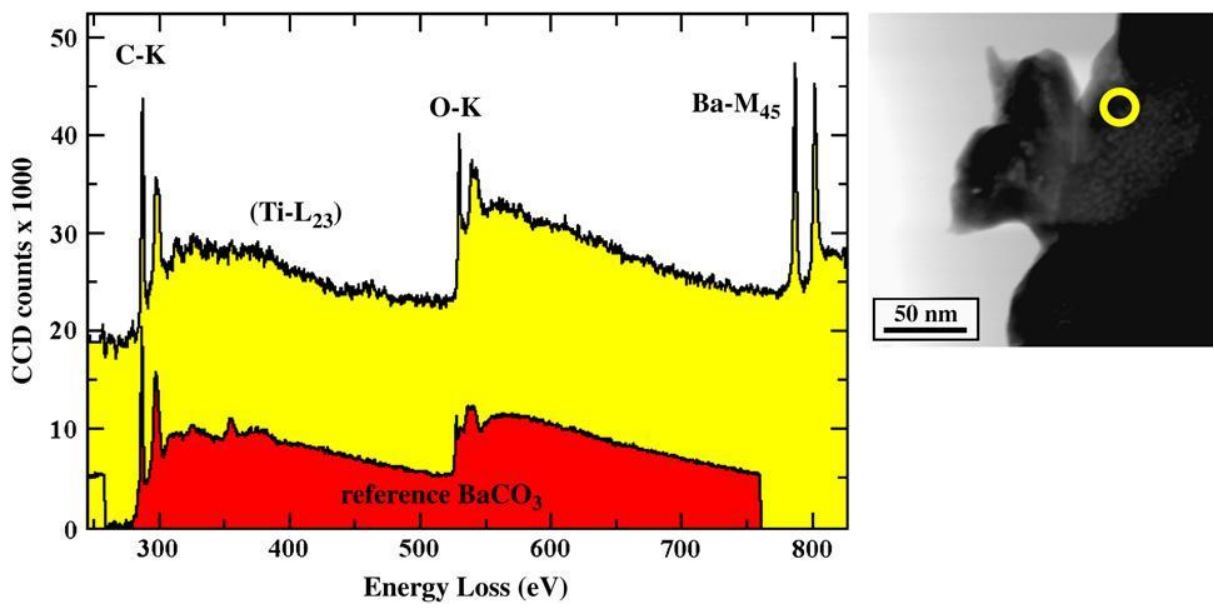

Fig. 5. EEL spectum of the Ba-rich regions in the 1,2-ethandiolato-derived intermediate (upper right: STEM image with indicated probe position). 


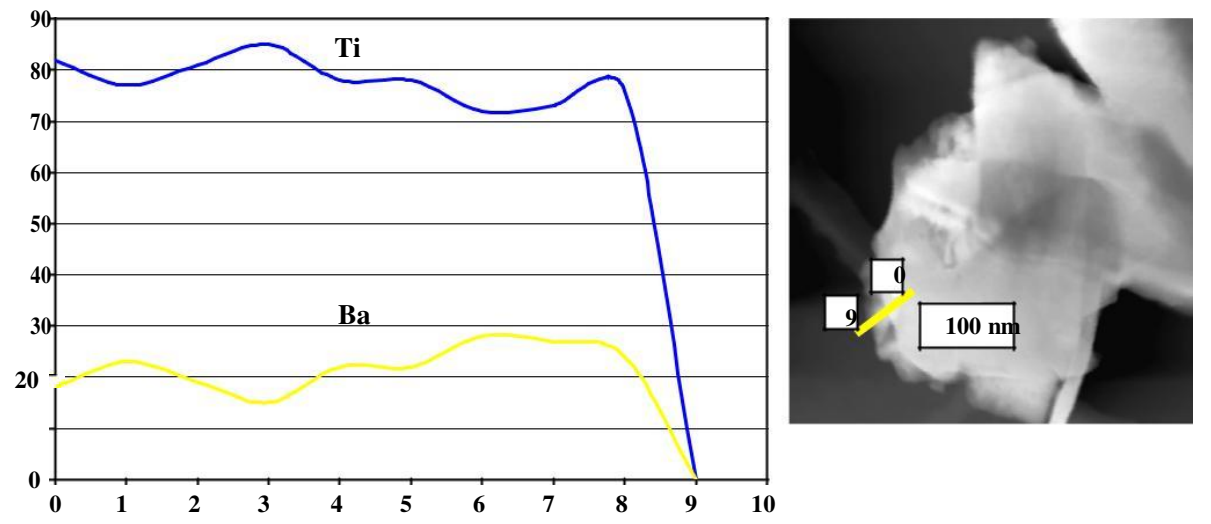

Fig. 6. The content of $\mathrm{Ba}$ and $\mathrm{Ti}$ (in at\%) in the Ti-rich regions formed in the 1,2-ethanediolato-derived intermediate (upper right: STEM dark field image with the EELS scan line marked).

in a mixed carbonate phase of the calcite-type structure, which remained unchanged at room temperature [20].

As mentioned above, the observed diffraction maxima in the powder XRD patterns of the intermediate reveal that the crystal structures of the Ba-rich phase bear a close resemblance to that of the calcite-type $\mathrm{BaCO}_{3}$. The observed hkl-dependent shift of the diffraction maxima towards higher $2 \theta$ values implies, however, that some foreign atoms or atom groups are present in the crystal structure of $\mathrm{BaCO}_{3}$ modifying the lattice parameters. As neither titanium cations nor titanate anions can be adopted by the calcite-type crystal structure for topological considerations, we conclude, that the only possible substitution to occur in this case is the substitution of $\mathrm{CO}_{3}^{2-}$ anion by $\mathrm{O}^{2-}$, leading to the formation of barium oxycarbonate with a general formula $\mathrm{BaO}_{\mathrm{x}}\left(\mathrm{CO}_{3}\right)_{1-\mathrm{x}}$. This is also confirmed by the results of our IR investigations and the related crystal structure analysis based on the Rietveld method [23].

\subsection{The experimentally observed Ti-rich phase}

In contrast to the Ba-rich regions, the Ti-rich areas do not show a long-range ordering of atoms and exhibit a continuously varying chemical composition, represented by the chemical formula $\mathrm{Ba}_{\mathrm{y}} \mathrm{TiO}_{2 \mathrm{py}}$, with 0.2 y 0.4 , determined by EELS.

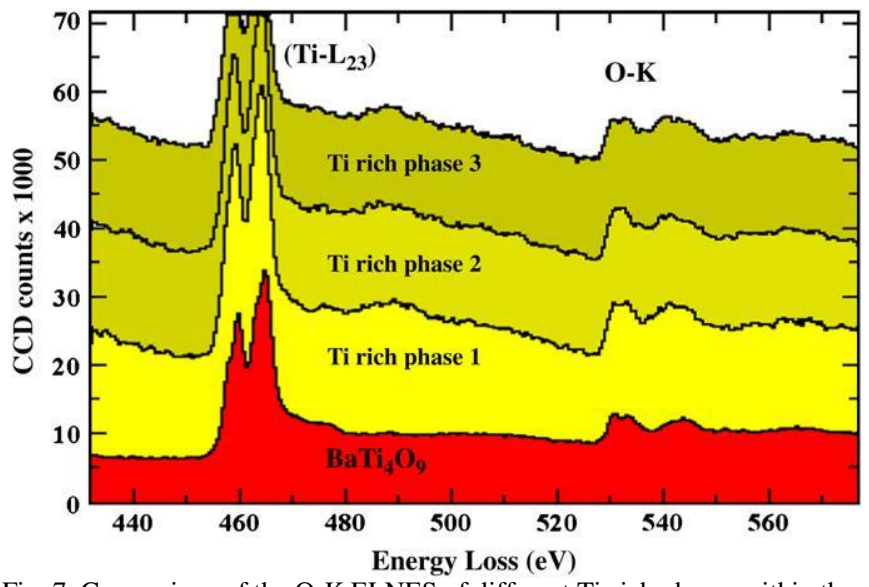

Fig. 7. Comparison of the O-K ELNES of different Ti-rich phases within the same sample with that of $\mathrm{BaTi}_{4} \mathrm{O}_{9}$.
In fact, there are several crystalline Ti-rich barium titanates known from the literature [24,25], corresponding to this general formula, e.g., $\mathrm{y}=0.22,0.25$ or 0.33 ; in fact, we have detected regions of such stoichiometries, but amorphous or possibly as a mixture of different nanocrystalline species. Altogether, the observed Ti-rich regions may be related to the formation processes of the known crystalline phases.

3.5. Phase evolution during thermal decomposition of Ba,Ti-precursor complexes

The scheme of the phase segregation in the intermediate product is shown in Fig. 9 (where $\mathrm{BaCO}_{3}$ may be imagined as consisting of $\mathrm{BaO}$ and $\mathrm{CO}_{2}$ ) and can be written as follows:

$(\mathrm{Ba}, \mathrm{Ti})$-precursor complex $\rightarrow(1-y) \mathrm{BaO}_{x}\left(\mathrm{CO}_{3}\right)_{1-x}$

$$
+\mathrm{Ba}_{y} \mathrm{TiO}_{2+y} \rightarrow \mathrm{BaTiO}_{3}
$$

The overall Ba:Ti ratio is predefined to be $1: 1$, according to the chemical composition of the precursors used. The content of bound $\mathrm{CO}_{2}$, however, varies, depending on the nature of ligands in the precursor complex and on the conditions of the

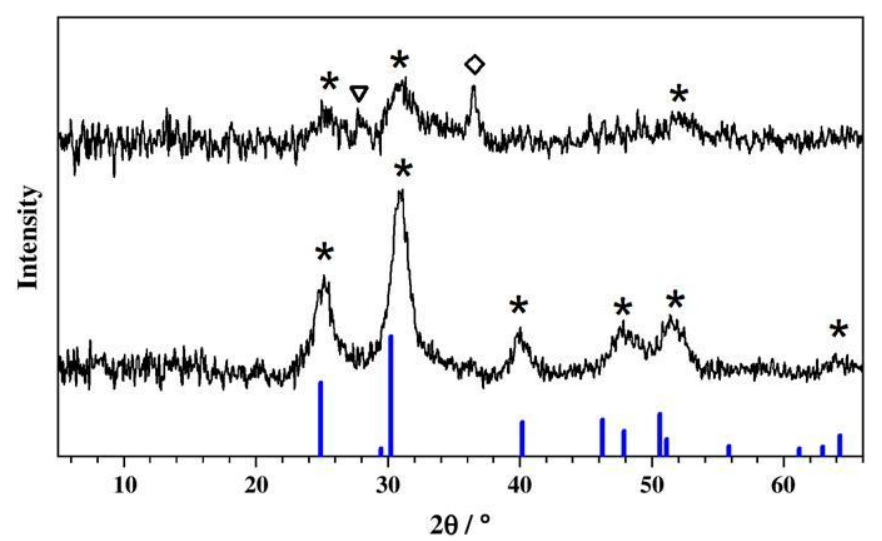

Fig. 8. Comparison of the experimentally observed powder XRD pattern for the 1,2-ethanediolato-derived [18] (top) and BTO-derived (bottom) intermediates with the calculated diffraction peak positions and intensities for calcite-type modification of $\mathrm{BaCO}_{3}$ (ICSD-27447). The Ba-rich phase is indicated by asterisk, the traces of whiterite by triangle and the traces of $\mathrm{BaTiO}_{3}$ by rhombus. 


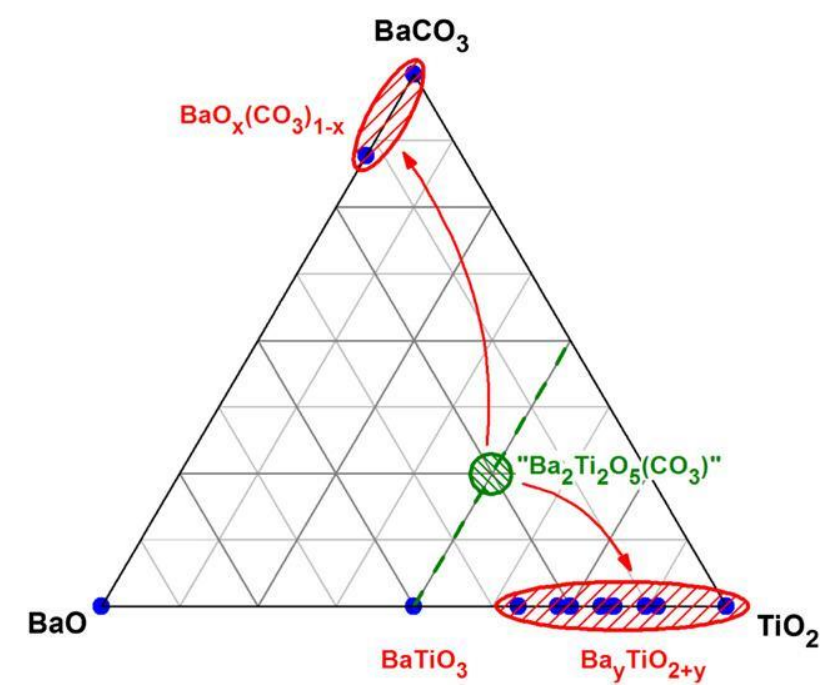

Fig. 9. Schematic presentation of phase relations in the Ba-Ti-C-O chemical system: the intermediate products of thermal decomposition, having predefined Ba:Ti ratio 1:1 and varying content of bound $\mathrm{CO}_{2}$ (green dashed line), do not form a separate phase, but segregate into Ba-rich and Ti-rich phases (red areas).

thermal decomposition. At high contents of the bound $\mathrm{CO}_{2}$, the formation of the mixture of $\mathrm{BaCO}_{3}$ and $\mathrm{TiO}_{2}$ is expected. With the lower content of the bound $\mathrm{CO}_{2}$ in the intermediate product the excessive $\mathrm{BaO}$ is "bound" by the $\mathrm{TiO}_{2}$ to form Ti-rich titanates and partially by $\mathrm{BaCO}_{3}$, which leads to the formation of calcite-type barium oxycarbonate, $\mathrm{BaO}_{\mathrm{x}}\left(\mathrm{CO}_{3}\right)_{1-\mathrm{x}}$. The subsequent interaction of the Ba-rich and Ti-rich phases leads then to the formation of $\mathrm{BaTiO}_{3}$.

We suppose that the content of the bound $\mathrm{CO}_{2}$ and the related content of excessive $\mathrm{BaO}$ in the system may have remarkable influence on the kinetics of grain growth and solid state reactions during the thermal decomposition.

\section{Conclusion}

The thermal decomposition of Ba,Ti-precursor complexes results in $\mathrm{Ba}$ and $\mathrm{Ti}$ segregation at the intermediate stage, enabling the formation of (i) a Ba-rich phase, which is supposed to be barium oxycarbonate with a general formula $\mathrm{BaO}_{\mathrm{x}}\left(\mathrm{CO}_{3}\right)_{1-\mathrm{x}}$ and structurally related to calcite-type $\mathrm{BaCO}_{3}$ and

(ii) different Ti-rich phases with the Ba:Ti ratio ranging from $1: 2.5$ to $1: 5.5$. Very small crystallite sizes of these phases (some ten nanometers in diameter) make it difficult to discern between them, even with highly local analytical methods (like EELS in the STEM mode).

In this contribution we have demonstrated, however, that the phase segregation indeed occurs during the process described above, which does not support the speculation of the formation of a homogeneous intermediate (Ba,Ti)oxycarbonate, which was widely supported by many authors. The low crystalline phase observed by powder XRD and commonly attributed to (Ba,Ti)-oxycarbonate in the literature has been shown to be barium oxycarbonate, containing no titanium.

Besides the barium oxycarbonate phase, the amorphous or nanocrystalline Ti-rich phases have been detected by EELS, being Ti-rich barium titanates. Many of such phases are well known from the literature in other contexts.

A general scheme of the $\mathrm{Ba}$ and $\mathrm{Ti}$ segregation at the intermediate stages during the thermal decomposition has been suggested. The $\mathrm{BaTiO}_{3}$ phase is formed as a result of solid state reactions between the Ba-rich and Ti-rich phases.

\section{References}

[1] G.A. Smolensky, J. Phys. Soc. (Jpn.) 28 (1970) 28

[2] A. Bauer, D. Bu“hling, H.-J. Gesemann, G. Helke, W. Schreckenbach, Technologie und Anwendung von Ferroelektrika, Akademische Verlagsgesellschaft, Leipzig, 1976.

[3] H.-P. Abicht, D. Vo“ltzke, A. Ro“der, R. Schneider, J. Woltersdorf, J. Mater. Chem. 7 (1997) 487e492.

[4] S. Urek, M. Drofenik, J. Eur. Ceram. Soc. 18 (1998) 279e286.

[5] M.P. Pechini, US patent 3,330,697, 11 July, 1967.

[6] D. Hennings, W. Mayr, J. Solid State Chem. 26 (1978) 329e338.

[7] S. Kumar, G.L. Messing, W.B. White, J. Am. Ceram. Soc. 76 (1993) $617 \mathrm{e} 624$

[8] W.-S. Cho, J. Phys. Chem. Solids 59 (1998) 659e666.

[9] J.-D. Tsay, T.-T. Fang, T.A. Gubiotti, J.Y. Ying, J. Mater. Sci. 33 (1998) $3721 \mathrm{e} 3727$.

[10] E.R. Leite, C.M.G. Sousa, E. Longo, J.A. Varela, Ceram. Int. 21 (1995) $143 \mathrm{e} 152$.

[11] B.J. Mulder, Ceram. Bull. 49 (1970) $990 \mathrm{e} 993$.

[12] H.S. Gopalakrishnamurthy, M.S. Rao, T.R.N. Kutty, J. Inorg. Nucl. Chem. 37 (1975) 891e898.

[13] O.O. Vasyl'kiv, A.V. Ragulya, V.V. Skorokhod, Powder Metall. Met. Ceram. 36 (1997) 277e282.

[14] S. Gablenz, D. Vo“ltzke, H.-P. Abicht, J. Neumann-Zdralek, J. Mater. Sci. Lett. 17 (1998) 537e539.

[15] S. Gablenz, H.-P. Abicht, E. Pippel, O. Lichtenberger, J. Woltersdorf, J. Eur. Ceram. Soc. 20 (2000) 1053e1060.

[16] R. Köferstein, L. Ja“ger, V. Lorenz, H.-P. Abicht, J. Woltersdorf, E. Pippel, H. Görls, Solid State Sci. 7 (2005) 1280e1288.

[17] W.S. Clabaugh, E.M. Swiggard, R. Gilchrist, J. Res. Nat. Bur. Stds. 56 (1956) $289 \mathrm{e} 291$.

[18] The powder X-ray diffraction pattern, presented for the 1,2-ethanediolato-derived intermediate in Fig. 8, refers to the sample obtained at $600 \mathrm{C}$. No diffraction peaks were observed for the intermediate obtained at $410 \mathrm{C}$, in spite of significant segregation of components detected by spatially resolved EELS (see text).

[19] P. Du'ran, D. Gutierrez, J. Tartaj, M.A. Ban ares, C. Moure, J. Eur. Ceram. Soc. 22 (2002) 797e807.

[20] J.J. Lander, J. Chem. Phys. 17 (17) (1949) 829e901.

[21] K.O. Strømme, Acta. Chem. Scand. A 29 (1975) 105e110.

[22] T. Nishino, T. Sakurai, N. Ishizawa, N. Mizutani, M. Kato, J. Solid State Chem. 69 (1987) 24e29.

[23] V. Ischenko, E. Pippel, R. Köferstein, H.-P. Abicht, J. Woltersdorf, Solid State Sci., submitted for publication.

[24] H.M. OBryan, J. Thomson, J. Am. Ceram. Soc. 57 (1974) 522e526.

[25] K.W. Kirby, B.A. Wechsler, J. Am. Ceram. Soc. 74 (1991) 1841e1847. 